\title{
Consumo de nutrientes e desempenho de ovinos alimentados com dietas à base de cana-de-açúcar hidrolisada
}

\author{
Acyr Wanderley de Paula Freitas(1), Fernanda Cipriano Rocha( ${ }^{(2)}$, Augusto Zonta(1), Jailson Lara Fagundes ${ }^{(1)}$, \\ Ricardo da Fonseca ${ }^{(2)}$, Márcia Cristina de Mello Zonta(1) e Fernanda Lopes Macedo(2)
}

(1)Agência Paulista de Tecnologia dos Agronegócios, Pólo da Alta Paulista, Caixa Postal 191, CEP 17800-000 Adamantina, SP. E-mail: apfreitas@apta.sp.gov.br, zonta@apta.sp.gov.br, jlfagundes@apta.sp.gov.br, marcia_zonta@yahoo.com (2)Universidade Estadual Paulista Júlio de Mesquita Filho, Campus Experimental de Dracena, Rodovia SP 294, Km 651, CEP 17900-000 Dracena, SP. E-mail: fecipri@terra.com.br, ricardo@dracena.unesp.br, fefisgirl@yahoo.com.br

\begin{abstract}
Resumo - O objetivo deste trabalho foi avaliar o consumo de nutrientes e o desempenho de ovinos alimentados com dietas à base de cana-de-açúcar in natura ou hidrolisada. Foram avaliados 18 ovinos, com aproximadamente $22 \pm 2,4 \mathrm{~kg}$ de peso vivo, distribuídos em delineamento de blocos ao acaso, com 6 repetições, e o peso dos animais foi utilizado como critério para sua distribuição nos blocos. Os animais receberam dietas completas com 50\% de volumoso (cana-de-açúcar in natura, tratada com 0,5 e com $0,9 \%$ de cal), e $50 \%$ de concentrado. As dietas foram formuladas de forma a atender às exigências de manutenção dos animais e os ganhos de $150 \mathrm{~g}$ por dia. As variáveis foram: o consumo e a digestibilidade dos nutrientes e o ganho em peso dos animais. A adição do hidróxido de cálcio aumentou a digestibilidade da fibra em detergente neutro. Não foi observada alteração no consumo de nutrientes ou melhora no ganho em peso dos animais alimentados com cana-deaçúcar, tratada com hidróxido de cálcio, a 0,5 e 0,9\%, em comparação à cana-de-açúcar in natura. A cana-deaçúcar com adição hidróxido de cálcio pode ser fornecida após 24 horas de armazenamento, sem prejuízo do desempenho dos animais.
\end{abstract}

Termos para indexação: Saccharum, hidrólise, ruminantes, tratamento alcalino.

\section{Nutrient consumption and performance by sheep fed with diets based on hydrolyzed sugarcane}

\begin{abstract}
The aim of this work was to evaluate the nutrient consumption and performance by animals fed with diets based on in natura or hydrolyzed sugarcane. Eighteen lambs, with approximately $22 \pm 2.4 \mathrm{~kg}$ body weight, were evaluated in randomized block design with 6 repetitions; the weight of the animals was utilized as a criterion for the distribution in the blocks. Animals received complete diets containing $50 \%$ forage (sugarcane in natura, treated with 0.5 and $0.9 \%$ lime), and $50 \%$ concentrate. Diets were formulated in order to meet animal maintenance demands and gains of $150 \mathrm{~g} /$ day. The variables evaluated were: nutrient consumption and digestibility, and animal weight gains. The addition of calcium hydroxide increased the digestibility of neutral detergent fiber. No alteration was observed on nutrient consumption nor improvement on animal weight gain fed on diets based on sugarcane treated with calcium hydroxide, at 0.5 and $0.9 \%$. Sugarcane with the addition of calcium hydroxide can be provided after 24 hours of storage, without reducing animal performance.
\end{abstract}

Index terms: Saccharum, hydrolysis, ruminants, alkali treatment.

\section{Introdução}

A cana-de-açúcar usada como recurso forrageiro para ruminantes, é uma das alternativas para se minimizar a nutrição inadequada dos animais, principalmente nos períodos de estiagem.

Os carboidratos estruturais da cana-de-açúcar são fonte potencial de energia de baixo custo para a alimentação desses animais. No entanto, tal potencial é limitado, em razão de suas baixas digestibilidade e taxa de degradação, com o conseqüente baixo consumo voluntário. Este fato está relacionado, principalmente, à estrutura da parede celular que protege os nutrientes da digestão microbiana no rúmen (Jung et al., 1993).

O consumo de alimentos é um aspecto fundamental na nutrição animal, uma vez que estabelece a ingestão de nutrientes e, portanto, determina a resposta do animal. Um ruminante alimentado à vontade só consegue ingerir quantidade limitada de cana-de-açúcar, uma vez que o consumo está diretamente relacionado ao conteúdo de fibra em detergente neutro (FDN). Quanto 
maior o teor de fibra da cana-de-açúcar e menor a digestibilidade dessa fração, menor será o consumo desse volumoso, ou seja, a taxa de digestão da fibra da cana-de-açúcar no rúmen é muito baixa, e o acúmulo de fibra não degradada no rúmen limita o consumo.

Vários estudos (Garmo, 1986; Andrade et al., 2001; Carvalho et al., 2006; Kawas et al., 2007; Pedroso et al., 2007) têm demonstrado que o tratamento de materiais fibrosos com álcalis melhora a digestibilidade. O fenômeno mais associado ao tratamento alcalino de volumosos é a solubilização parcial de hemicelulose, lignina e sílica, e a hidrólise dos ésteres dos ácidos urônico e acético. O tratamento com álcali também pode levar à quebra de pontes de hidrogênio na celulose (Berger et al., 1994).

O hidróxido de sódio $(\mathrm{NaOH})$ é uma das substâncias alcalinas mais utilizada com esse propósito (Pires et al., 2006). Apesar dos significantes benefícios da utilização do $\mathrm{NaOH}$, na melhora do valor nutritivo de alimentos ricos em carboidratos estruturais, sua aplicação é limitada por ser considerado nocivo ao homem, aos animais e ao meio ambiente.

A cal microprocessada, encontrada nas formas de óxido de cálcio $(\mathrm{CaO})$ e hidróxido de cálcio $\left(\mathrm{Ca}(\mathrm{OH})_{2}\right)$, surge como alternativa segura e de baixo custo ao hidróxido de sódio. Estudos conduzidos por Garmo (1986) evidenciaram incrementos de 13 a $20 \%$, na digestibilidade in vitro da matéria seca (MS) da palha de aveia tratada com $\mathrm{Ca}(\mathrm{OH})_{2}$. No entanto, Bass et al. (1982), não observaram efeito significativo do tratamento com $\mathrm{Ca}(\mathrm{OH})_{2}$ sobre a digestibilidade da palha de trigo.

Embora um número cada vez maior de produtores esteja adotando o tratamento da cana-de-açúcar com a cal microprocessada, na forma de $\mathrm{CaO}$ ou $\mathrm{Ca}(\mathrm{OH})_{2}$, não são conhecidos dados na literatura a respeito da dose a ser utilizada e, principalmente, sobre o valor nutritivo da cana-de-açúcar submetida a esses tratamentos.

$\mathrm{O}$ interesse pelo uso da cana-de-açúcar hidrolisada com hidróxido de cálcio, na alimentação de ovinos, é bastante recente, todavia, é reduzido o número de trabalhos na literatura que avaliam o valor nutritivo desse alimento. A maioria dos pesquisadores se refere ao uso do hidróxido de sódio ou avaliaram apenas a digestibilidade in vitro.

O objetivo deste trabalho foi avaliar o consumo e o desempenho de ovinos, alimentados com dietas à base de cana-de-açúcar in natura ou hidrolisada.

\section{Material e Métodos}

Oexperimento foi conduzido no Pólo daAlta Paulista, sediado em Adamantina, SP, de agosto a novembro de 2007. Utilizou-se a variedade de cana-de-açúcar IAC 86-2480, desenvolvida para fins forrageiros, pelo Instituto Agronômico (IAC, Campinas, SP).

Foram utilizados 18 ovinos, com aproximadamente $22 \pm 2,4 \mathrm{~kg}$ de peso vivo (PV), distribuídos em delineamento de blocos ao acaso com 6 repetições, em que se utilizou o peso dos animais, como critério para sua distribuição nos blocos.

Os animais receberam dietas completas com $50 \%$ de volumoso (cana-de-açúcar in natura, tratada com 0,5 e $0,9 \%$ de cal), e $50 \%$ de concentrado. As dietas foram formuladas de forma a atender às exigências de manutenção dos animais e os ganhos de $150 \mathrm{~g}$ por dia. Na Tabela 1, está apresentada a composição bromatológica do concentrado e da cana-de-açúcar, nos diferentes tratamentos, e na Tabela 2, a composição bromatológica das dietas experimentais.

Em período pré-experimental (sete dias), os animais foram pesados, vermifugados e distribuídos em baias individuais, com comedouros e bebedouros. Tal período foi adotado para a adaptação dos animais às dietas e às instalações experimentais.

$\mathrm{O}$ desempenho dos animais foi avaliado com base no ganho em peso. Para tanto, foram efetuadas pesagens no início e no final do experimento, além das intermediárias a cada 14 dias, o que totalizou 42 dias experimentais, após sete dias de adaptação às dietas. As pesagens foram precedidas de jejum de 12 horas.

A alimentação foi pesada e fornecida diariamente às $7 \mathrm{e}$ às $15 \mathrm{~h}$, e permitiram-se sobras em torno de $10 \%$. As sobras foram retiradas e pesadas diariamente, para determinação do consumo diário.

Tabela 1. Composição bromatológica do concentrado e da cana-de-açúcar, nos diferentes tratamentos ${ }^{(1)}$.

\begin{tabular}{lrccc}
\hline Item & Concentrado & \multicolumn{3}{c}{ Cana-de-açúcar } \\
\cline { 3 - 5 } & & In natura & $0,5 \%$ cal & $0,9 \%$ cal \\
\hline MS (\%) & 88,7 & 28,5 & 30,7 & 29,0 \\
PB (\% MS) & 32,6 & 2,24 & 2,24 & 2,46 \\
FDN (\% MS) & 16,2 & 44,0 & 44,4 & 43,2 \\
FDA (\% MS) & 2,7 & 30,2 & 28,9 & 26,8 \\
EE (\% MS) & 2,0 & 0,39 & 0,40 & 0,50 \\
CT (\% MS) & 60,0 & 94,0 & 92,2 & 89,9 \\
MM (\% MS) & 5,3 & 3,4 & 5,2 & 7,0 \\
Ca (g kg $\left.{ }^{-1}\right)$ & 5,7 & 1,9 & 11,4 & 21,3 \\
P (g kg $\left.{ }^{-1}\right)$ & 5,8 & 0,3 & 0,4 & 0,4 \\
\hline
\end{tabular}


As soluções de $\mathrm{Ca}(\mathrm{OH})_{2}$, utilizadas no tratamento da cana, foram preparadas a $25 \%$ (100 mL de água para cada $25 \mathrm{~g}$ de $\left.\mathrm{Ca}(\mathrm{OH})_{2}\right)$, conforme os níveis estabelecidos no delineamento experimental. A composição da cal usada se encontra na Tabela 3. O tratamento foi realizado imediatamente após o corte da cana, e o material tratado foi fornecido após 24 horas de armazenamento em local coberto e com piso de concreto. As médias das temperaturas máximas e mínimas, no período experimental, foram $34,6 \pm 2,9^{\circ} \mathrm{C}$ e $19,8 \pm 1,9^{\circ} \mathrm{C}$, respectivamente, e a média da umidade relativa, às $7 \mathrm{~h} 30$, foi de $79,9 \pm 10,1 \%$.

Foram coletadas amostras diárias dos alimentos fornecidos e das respectivas sobras, e foi realizada uma amostra composta a cada semana, que foram identificadas e acondicionadas em freezer, para posteriores análises laboratoriais. Entre o $22^{\circ}$ e $27^{\circ}$ dias experimentais, foram coletadas amostras de fezes, a cada 26 horas, para a estimativa da produção fecal, tendo-se utilizado fibra em detergente ácido indigestível (FDAi) como indicador interno, conforme Ítavo et al. (2002). Nesse procedimento, as amostras de alimentos, sobras e fezes foram colocadas em sacos "ankon" (Filter bags F57), incubadas no rúmen pelo período de 144 horas. O material remanescente da incubação foi previamente lavado com água e, em seguida, submetido à extração com detergente ácido, cujo resíduo foi considerado FDAi. Para determinação dos coeficientes de digestibilidade aparente dos nutrientes (CD), foi utilizada a seguinte equação: $\mathrm{CD}=100[$ (consumo do nutriente - nutriente nas fezes)/consumo do nutriente].

As amostras de sobras, alimentos e fezes foram secadas em estufa ventilada a $60^{\circ} \mathrm{C}$, por 72 horas, para se proceder à moagem. Ingredientes da ração e o material

Tabela 2. Composição bromatológica das dietas experimentais ${ }^{(1)}$.

\begin{tabular}{lccc}
\hline Item & \multicolumn{3}{c}{ Tratamentos } \\
\cline { 2 - 4 } & Controle & $0,5 \%$ cal & $0,9 \%$ cal \\
\hline MS (\%) & 58,6 & 59,7 & 58,8 \\
PB (\% MS) & 17,4 & 17,4 & 17,5 \\
FDN (\% MS) & 30,1 & 30,3 & 29,7 \\
FDA (\% MS) & 16,5 & 15,8 & 14,8 \\
EE (\% MS) & 1,2 & 1,2 & 1,3 \\
CT (\% MS) & 77,0 & 76,1 & 75,0 \\
MM (\% MS) & 4,4 & 5,3 & 6,2 \\
Ca (g kg $\left.{ }^{-1}\right)$ & 3,8 & 8,6 & 13,5 \\
P (g kg $\left.{ }^{-1}\right)$ & 3,0 & 3,1 & 3,1 \\
\hline
\end{tabular}

${ }^{(1)} \mathrm{MS}$, matéria seca; $\mathrm{PB}$, proteína bruta;FDN, fibra em detergente neutro; FDA, fibra em detergente ácido; EE, extrato etéreo; CT, carboidratos totais; MM, matéria mineral. secado em estufa foram moídos em moinho tipo Wiley, com peneira com malha de $1 \mathrm{~mm}$, acondicionados em frascos com tampa e armazenados para posteriores análises laboratoriais.

Os materiais foram analisados quanto a: conteúdo em matéria seca (MS), matéria orgânica, proteína bruta (PB), fibra em detergente neutro (FDN), fibra em detergente ácido (FDA), lignina e extrato etéreo (EE), segundo Silva \& Queiroz (2002). Os teores de carboidratos totais (CT) foram calculados segundo as equações de Sniffen et al. (1992), em que: CT $=100$ - (\%PB + \%EE + \%cinzas), enquanto os teores de carboidratos não fibrosos $(\mathrm{CNF})$ foram calculados pela fórmula $\mathrm{CNF}=\mathrm{CT}-\mathrm{FDN}$.

Os resultados foram submetidos à análise de variância, e a comparação das médias foi feita pelo teste de Student-Newman-Keuls (SNK), a 5\% de probabilidade, por meio do sistema de análises estatísticas e genéticas - SAEG -, versão 9.1 (Euclides, 2001).

\section{Resultados e Discussão}

Os valores médios e os coeficientes de variação dos parâmetros de desempenho estão apresentados na Tabela 4. Não houve diferença $(p>0,05)$ estatística em relação a nenhuma das variáveis analisadas. O consumo diário de matéria seca foi muito semelhante entre os tratamentos, quando avaliados em gramas por dia e em percentagem do peso vivo.

O consumo médio de matéria seca em gramas por dia e a percentagem do peso vivo observados foram de $954,8 \mathrm{~g}$ de MS por dia e 3,9\%, respectivamente. Esses valores estão de acordo com as recomendações do NRC (National Research Council, 1985) para ovinos que é o de consumo de $1 \mathrm{~kg}$ de MS por dia, para cordeiros com peso médio de $20 \mathrm{~kg}$ e ganho de $150 \mathrm{~g}$. Mendes (2006) trabalhou com dietas semelhantes, que continham

Tabela 3. Composição química da cal microprocessada $\left(\mathrm{Ca}(\mathrm{OH})_{2}\right)$.

\begin{tabular}{lcc}
\hline Componente & Especificação & Concentração (\%) \\
\hline Óxido de magnésio & - & 0,40 \\
Óxido de alumínio & Máximo 1\% & 0,54 \\
Sílica & Máximo 5\% & 3,40 \\
Óxido de cálcio & Mínimo 50\% & 55,10 \\
Óxido de cálcio disponível & - & 50,10 \\
Óxido de ferro & Máximo 1\% & 0,28 \\
\hline${ }^{(1)}$ MS, matéria seca; PB, proteína bruta;FDN, fibra em detergente neutro; \\
FDA, fibra em detergente ácido; EE, extrato etéreo; CT, carboidratos totais; \\
MM, matéria mineral.
\end{tabular}

Pesq. agropec. bras., Brasília, v.43, n.11, p.1569-1574, nov. 2008 
$50 \%$ de cana-de-açúcar in natura, e também obteve valores de consumo de matéria seca de 3,9\% do peso vivo. Do mesmo modo, Ranjit et al. (2002), ao avaliar o desempenho de cordeiros alimentados com rações que continham silagem de milho, observaram valores de consumo de matéria seca em torno de 920 g de MS por dia.

O ganho em peso médio e a conversão alimentar observados (Tabela 4) foram de 117, 108 e $137 \mathrm{~g}$ por dia e 8,2, 8,7 e $7 \mathrm{~kg}$ de $\mathrm{MS} \mathrm{kg}^{-1}$ de ganho, nos tratamentos cana in natura, e as tratadas com $0,5 \mathrm{e}$ $0,9 \%$ de cal, respectivamente. O tratamento da canade-açúcar com hidróxido de cálcio não afetou o ganho em peso e a conversão alimentar dos ovinos. Neste trabalho o valor relativo à conversão alimentar está próximo do obtido por Mendes (2006), em que foram observados 7,5 $\mathrm{kg}^{\mathrm{de}} \mathrm{MS} \mathrm{kg}^{-1}$ de ganho para as dietas com $50 \%$ de cana-de-açúcar. Os valores de ganho em peso foram semelhantes aos obtidos por Castrillón et al. (1978). Esses autores avaliaram a adição de $\mathrm{NaOH}$ na ensilagem da cana-de-açúcar, e observaram valores de 133 e $127 \mathrm{~g}$ por dia, em relação às silagens feitas a partir de material fresco ou de material emurchecido, respectivamente.

Ítavo et al. (2006) ao trabalhar com cordeiros confinados em fase de terminação, obtiveram melhores valores de conversão alimentar de 5,05 a $6,86 \mathrm{~kg}$ de MS kg-1 de ganho, em dietas à base de $50 \%$ de capimelefante e $50 \%$ de concentrado, que continham grãos de milho ou sorgo, ensilados ou não.

Não foi observada diferença entre os tratamentos, no que se refere ao consumo dos nutrientes em gramas por dia (Tabela 5), com exceção do consumo de cálcio. Este resultado era esperado, em razão do aumento do fornecimento de cálcio com o aumento na dose de cal, no tratamento da cana-de-açúcar; no entanto, esses níveis não ultrapassaram o máximo de tolerância ao cálcio para ovinos. A relação cálciofósforo não ultrapassou o nível de 4:1.
Moraes (2006) ao trabalhar com novilhas de corte, não observou aumento no consumo de MS e FDN, ao adicionar $1 \%$ de cal na cana-de-açúcar. Pontes (2007) avaliou dietas para ovinos e não observou diferença nos consumos de MS, matéria orgânica, $\mathrm{PB}, \mathrm{CD}$ e de nutrientes digestíveis totais com aplicação de $0,5 \%$ de cal.

Fimbres et al. (2002) ao avaliar teores crescentes de feno na alimentação de cordeiros $(0,10,20$ e $30 \%$ da MS), encontraram valores máximos de consumo de $1,25 \mathrm{~kg}$ de MS por dia e de $350 \mathrm{~g}$ de FDN por dia, em animais que receberam dieta com $30 \%$ de feno. Os valores obtidos por esses autores são inferiores aos observados por Mendes (2006), em cordeiros alimentados com dietas à base de cana-de-açúcar desintegrada in natura $(1,75 \mathrm{~kg}$ de MS por dia e $610 \mathrm{~g}$ de FDN por dia). Com esses dados, pode-se inferir que o teor de FDN das dietas não foi fator limitante para o consumo de MS dos animais, que foi de 271,7 $\mathrm{g}$ de FDN por dia (Tabela 5). Cardoso et al. (2006) observaram que o consumo de MS, de cordeiros alimentados com dietas que continham diferentes teores de FDN $(25,31,37 \mathrm{e}$ $43 \%$ na MS), diminuiu linearmente com o aumento do teor de FDN da dieta.

Não foi verificada diferença $(p>0,05)$ nos coeficientes de digestibilidade da MS e da $\mathrm{PB}$, no entanto os coeficientes de digestibilidade da FDN foram superiores $(\mathrm{p}<0,05)$, nos tratamentos com a cal, em comparação com a cana in natura. Conforme pode ser observado na Tabela 6, a cana-de-açúcar apresentou digestibilidade da FDN de 38,2, 45, 1 e 46,7\% nos tratamentos in natura, com 0,5 e $0,9 \%$ de cal, respectivamente. Ao se compararem as médias obtidas para a cana-de-açúcar tratada com as da cana in natura, pode-se observar que o tratamento melhorou a digestibilidade da FDN em 18 e $22 \%$, em relação às doses de 0,5 e $0,9 \%$, respectivamente.

Esses resultados estão de acordo com os obtidos por Oliveira et al. (2007), em que foram observadas semelhanças, nas médias dos coeficientes de

Tabela 4. Desempenho dos ovinos alimentados com dieta à base de cana-de-açúcar in natura ou hidrolisada.

\begin{tabular}{lccrr}
\hline Parâmetro & \multicolumn{3}{c}{ Tratamentos } & CV (\%) \\
\cline { 2 - 4 } & In natura & Hidrolisada 0,5\% cal & Hidrolisada 0,9\% cal & - \\
PV inicial $(\mathrm{kg})$ & 22,9 & 22,3 & 22,9 & - \\
PV final $(\mathrm{kg})$ & 27,9 & 26,9 & 28,7 & 15,4 \\
Consumo de MS (g dia $\left.{ }^{-1}\right)$ & 965,8 & 935,9 & 962,6 & 7,2 \\
Consumo de MS (\% PV) & 3,97 & 3,96 & 3,93 & 35,4 \\
Ganho em peso diário (g) & 117 & 108 & 137 & 34,4 \\
Conversão alimentar (kg MS por kg GDP) & 8,2 & 8,7 & 7,0 & \\
\hline
\end{tabular}


Tabela 5. Consumo médio de proteína bruta (CPB), fibra em detergente neutro (CFDN), cálcio (CCa) e fósforo (CP) em gramas por dia, em razão dos tratamentos ${ }^{(1)}$.

\begin{tabular}{lcccc}
\hline Item & \multicolumn{3}{c}{ Tratamentos } & CV (\%) \\
\cline { 2 - 4 } & In natura & $0,5 \% \mathrm{cal}$ & $0,9 \% \mathrm{cal}$ & \\
\hline $\mathrm{CPB}$ & $196,9 \mathrm{a}$ & $193,7 \mathrm{a}$ & $192,7 \mathrm{a}$ & 14,8 \\
$\mathrm{CFDN}$ & $276,3 \mathrm{a}$ & $270,6 \mathrm{a}$ & $268,4 \mathrm{a}$ & 23,9 \\
$\mathrm{CCa}$ & $4,1 \mathrm{c}$ & $8,4 \mathrm{~b}$ & $13,5 \mathrm{a}$ & 19,5 \\
$\mathrm{CP}$ & $3,5 \mathrm{a}$ & $3,4 \mathrm{a}$ & $3,5 \mathrm{a}$ & 15,6 \\
\hline
\end{tabular}

${ }^{(1)}$ Médias seguidas de letras diferentes, na mesma linha, diferem entre si pelo teste SNK, a $5 \%$ de probabilidade.

Tabela 6. Médias dos coeficientes de digestibilidade da matéria seca (DMS), da proteína bruta (DPB) e da fibra em detergente neutro (DFDN) ${ }^{(1)}$.

\begin{tabular}{lcccc}
\hline Item & \multicolumn{3}{c}{ Tratamentos } & CV (\%) \\
\cline { 2 - 4 } & In natura & $0,5 \%$ cal & $0,9 \%$ cal & \\
\hline DMS & $75,1 \mathrm{a}$ & $78,3 \mathrm{a}$ & $78,3 \mathrm{a}$ & 4,7 \\
DPB & $70,4 \mathrm{a}$ & $77,9 \mathrm{a}$ & $77,2 \mathrm{a}$ & 8,1 \\
DFDN & $38,2 \mathrm{~b}$ & $45,1 \mathrm{a}$ & $46,7 \mathrm{a}$ & 7,1 \\
\hline
\end{tabular}

${ }^{(1)}$ Médias seguidas de letras iguais, na mesma linha, diferem entre si pelo teste SNK, a $5 \%$ de probabilidade.

digestibilidade da MS da cana-de-açúcar hidrolisada com 0,5 e 1,0\% de cal. Andrade et al. (2001) ao avaliar a aplicação de $1 \%$ de hidróxido de sódio na cana-de-açúcar para ovinos, não observou melhora nos coeficientes de digestibilidade da MS e da FDN. No entanto, Moraes (2006) observou diminuição na digestibilidade da FDN e da PB, com adição de $1 \%$ de cal a cana-de-açúcar.

Apesar de ter ocorrido aumento significativo na digestibilidade da FDN, a hidrólise com o hidróxido de cálcio não foi suficiente para aumentar a digestibilidade e o consumo dos demais nutrientes, no período avaliado.

\section{Conclusão}

O consumo de nutrientes e o ganho em peso de ovinos não são alterados pela alimentação com cana-de-açúcar tratada com hidróxido de cálcio a 0,5 e $0,9 \%$.

\section{Agradecimentos}

À Fundação de Amparo à Pesquisa do Estado de São Paulo, pelo financiamento.

\section{Referências}

ANDRADE, J.B. de; FERRARI JÚNIOR, E.; BRAUN, G. Valor nutritivo de cana-de-açúcar tratada com hidróxido de sódio e acrescida de rolão-de-milho. Pesquisa Agropecuária Brasileira, v.36, p.1265-1268, 2001.

BASS, J.M.; PARKINS, J.J.; FISHWICK, G. The effect of calcium hydroxide treatment on the digestibility of chopped oat straw supplemented with a solution containing urea, calcium, phosphorus, sodium, trace elements and vitamins. Animal Feed Science and Technology, v.7, p.93-100, 1982.

BERGER, L.L.; FAHEY JUNIOR, G.C.; BOURQUIN, L.D.; TITGEMEYER, E.C. Modification of forage quality after harvest. In: FAHEY JUNIOR, G.C. Forage quality, evaluation, and utilization. Wisconsin: ASA, 1994. p.922-966.

CARDOSO, A.R.; PIRES, C.C.; CARVALHO, S.; GALVANI, D.B.; JOCHIMS, F.; HASTENPFLUG, M.; WOMMER, T.P. Consumo de nutrientes e desempenho de cordeiros alimentados com dietas que contêm diferentes níveis de fibra em detergente neutro. Ciência Rural, v.36, p.215-221, 2006.

CARVALHO, G.G.P. de; PIRES, A.J.V.; VELOSO, C.M.; MAGALHÃES, A.F.; FREIRE, M.A.L.; SILVA, F.F. da; SILVA, R.R.; CARVALHO, B.M.A. de. Valor nutritivo do bagaço de cana-de-açúcar amonizado com quatro doses de uréia. Pesquisa Agropecuária Brasileira, v.41, p.125-132, 2006.

CASTRILlÓN, M.V.; SHIMADA, A.S. Manipulación de la fermentación en ensilajes de caña de azúcar y su valor alimenticio para borregos. Técnica Pecuaria en México, v.35, p.48-55, 1978.

EUCLIDES, R.F. Manual de utilização do Programa SAEG: sistema para análises estatísticas e genéticas. Viçosa: UFV, 2001. 59p.

FIMBRES, H.; KAWAS, J.R.; HERNÁNDEZ-VIDAL, G.; PICÓNRUBIO, J.F.; LU, C.D. Nutrient intake, digestibility, mastication and ruminal fermentation of lambs fed finishing ration with various forage levels. Small Ruminant Research, v.43, p.275-281, 2002.

GARMO, T.H. Treatment of straw with sodium, potassium and calcium hydroxide in laboratory scale. Norway: Agricultural University of Norway, 1986. 60p. (Report, n.239).

ÍTAVO, C.C.B.F.; MORAIS, M. da G.; ÍTAVO, L.C.V.; SOUZA, A.R.D.L. de; OSHIRO, M.M.; BIBERG, F.A.; COSTA, C.; JOBIM, C.C.; LEMPP, B. Efeitos de diferentes fontes de concentrado sobre o consumo e a produção de cordeiros na fase de terminação. Revista Brasileira de Zootecnia, v.35, p.139-146, 2006.

ÍTAVO, L.C.V.; VALADARES FILHO, S. de C.; SILVA, F.F. da; VALADARES, R.F.D.; PAULINO, M.F.; ÍTAVO, C.C.B.F.; MORAES, E.H.B.K. de. Comparação de indicadores e metodologia de coleta para estimativas de produção fecal e fluxo de digesta em bovinos. Revista Brasileira de Zootecnia, v.31, p.1833-1839, 2002.

JUNG, H.G.; BUXTON, D.R.; HATFIELD, R.D.; RALPH, J. Forage cell wall structure and digestibility. Wisconsin: ASA, 1993.

KAWAS, J.R.; GARCÍA-CASTILLO, R.; FIMBREZ-DURAZO, H.; GARZA-CAZARES, F.; HERNÁNDES-VIDAL， J.F.G.; OLIVARES-SÁENZ, E.; LU, C.D. Effects of sodium bicarbonate and yeast on nutrient intake, digestibility, and ruminal fermentation of light-weight lambs fed finishing diets. Small Ruminant Research, v.67, p.149-156, 2007. 
MENDES, C.Q. Silagem de cana-de-açúcar na alimentação de ovinos e caprinos: valor nutritivo, desempenho e comportamento ingestivo. 2006. 103p. Dissertação (Mestrado) - Escola Superior de Agricultura Luiz de Queiroz, Piracicaba.

MORAES, K.A.K. Desempenho produtivo de novilhas de corte alimentadas com cana-de-açúcar tratada com óxido de cálcio e diferentes ofertas de concentrado. 2006. 60p. Dissertação (Mestrado) - Universidade Federal de Viçosa, Viçosa.

NATIONAL RESEARCH COUNCIL. Nutrient requirements of sheep. $6^{\text {th }}$ ed. Washington: National Academic Press, 1985. 99p.

OLIVEIRA, M.D.S.; ANDRADE, A.T.; BARBOSA, J.C.; SILVA, T.M.;FERNANDES,A.R.M.; CALDEIRÃO, E.; CARABOLANTE, A. Digestibilidade da cana-de-açúcar hidrolisada, in natura e ensilada para bovinos. Ciência Animal Brasileira, v.8, p.41-50, 2007.

PEDROSO, A. de F.; NUSSIO, L.G.; LOURES, D.R.S.; PAZIANI, S.F.; IGARASI, M.S.; COELHO, R.M.; HORII, J.; RODRIGUES, A. de A. Efeito do tratamento com aditivos químicos e inoculantes bacterianos nas perdas e na qualidade de silagens de cana-de-açúcar. Revista Brasileira de Zootecnia, v.36, p.558-564, 2007.
PIRES, A.J.V.; REIS, R.A.; CARVALHO, G.G.P. de; SIQUEIRA, G.R.; BERNARDES, T.F. Bagaço de cana-de-açúcar tratado com hidróxido de sódio. Revista Brasileira de Zootecnia, v.35, p.953-957, 2006.

PONTES, R.A.M. Cana-de-açúcar in natura ou ensilada com óxido de cálcio e uréia em dietas de ovinos. 2007. 60p. Dissertação (Mestrado) - Universidade Federal de Viçosa, Viçosa.

RANJIT, N.K.; TAYLOR, C.C.; KUNG JUNIOR, L. Effect of Lactobacillus buchneri 40788 on the fermentation, aerobic stability and nutritive value of maize silage. Grass and Forage Science, v.57, p.73-81, 2002.

SILVA, D.J.; QUEIROZ, A.C. Análise de alimentos: métodos químicos e biológicos. Viçosa: UFV, 2002. 235p.

SNIFFEN, C.J.; O'CONNOR, J.D.; VAN SOEST, P.J.; FOX, D.G.; RUSSEL, J.B. A net carbohydrate and protein system for evaluating cattle diets: II. Carbohydrate and protein availability. Journal of Animal Science, v.70, p.3562-3577, 1992.

Recebido em 11 de agosto de 2008 e aprovado em 14 de outubro de 2008 